\title{
An Empirical Study on the Factors Influencing the Innovation of Internet Business Model
}

\author{
Zhu Zongqian, Shang Yanying*, Yan Tong, Zhang Ruocheng \\ School of Economics and Management, Xi' an University of Technology, Xi'an, China \\ Email address: \\ 505276306@qq.com (Shang Yanying) \\ ${ }^{*}$ Corresponding author
}

To cite this article:

Zhu Zongqian, Shang Yanying, Yan Tong, Zhang Ruocheng. An Empirical Study on the Factors Influencing the Innovation of Internet Business Model. Science Journal of Business and Management. Vol. 6, No. 2, 2018, pp. 55-65. doi: 10.11648/j.sjbm.20180602.14

Received: May 30, 2018; Accepted: August 1, 2018; Published: August 13, 2018

\begin{abstract}
On the mode of integration of the relevant literature and interviews in the enterprise, Internet background from the practice of value creation from the perspective of the construction of driving factors identification framework of business model innovation, using exploratory factor analysis to extract the common factor of Internet business model innovation factors. After factor analysis, the common factor is named. Conclusion: from the practice of value creation of 4 common factors were extracted from the perspective of industry chain integration driven subject, degree, Value flow degree and outside the enterprise resource integration mode and profit mode. Enterprises should strengthen the complementarity and stability of cooperative networks and expand the channel resources of partners from the angle of industry chain and driving agent. Strengthen the knowledge absorption ability of the staff and the innovation ability of the product orientation of the enterprise, and control the replicability of the enterprise value-added service on the basis of ensuring the data security of the enterprise. Enterprises should pay attention to marginal users, strengthen the win-win of enterprise cooperation network and innovation of revenue channels. From the perspective of internal resource integration and external resource integration, enterprises should strengthen communication with users and suppliers, improve customer satisfaction, and explore the depth of value.
\end{abstract}

Keywords: Internet, Business Model Innovation, Influencing Factors, Empirical Research

\section{Introduction}

In July 4th 2015, the State Council issued the guiding opinion on actively promoting the "Internet+" action. Premier Li Keqiang put forward the "Internet+" action plan. The concept of "Internet" has become a hot topic among enterprises and academia, and the construction of enterprise informatization has been upgraded from the stage of "+Internet" to the stage of Internet. Because of its open sharing, coordination, etc., the constantly changing external environment and user demand increase gradually brings new opportunities and challenges for the enterprise management. With the development of Internet information technology, enterprises to formulate and implement related Internet business strategy, because the business model determines the core competitiveness of enterprises, enterprises have to subvert the optimization and innovation and creativity to the traditional business model by the Internet technology, has formed the new products, new services, new technologies, new formats etc. "The Internet" the competitive advantage of the business model, because the exploration period development period in the enterprise practice and academic research, from the perspective of practice to help enterprises how to "Internet" business model innovation, the first problem is: "the Internet" business model innovation driven further, What are the influencing factors of the Internet business model innovation?

\section{Theory and Analysis Framework}

\subsection{The Definition of Concept}

"The Internet" concept was first proposed by China Analysys International chairman Yu Yang, it is proposed on the basis of the technical development of the international economy more focus on combining the development status and characteristics of China's enterprises, have a certain 
understanding of the concept of the "Internet" in academic circles. Dan Fengru (2015) [1] from the industrial point of view that is not the "Internet" multiplication addition, it is a kind of chemical reaction rather than mathematical formula, is not the simple addition of the two industries, but two kinds of industry integration and reconstruction; Liu Zhou (2015) [2] the view that the "Internet" is the technology, from the social system and economic system. Cross border integration, is a new generation of information technology to construct the information system with the network responsible for the physical; the "Internet" is defined as: a new ecological upgrade traditional industries and create thinking of using the Internet and technology.

This paper defines the concept of Internet business model on the basis of analyzing the characteristics of cloud service mode and network crowdsourcing mode.

On the basis of analyzing the characteristics of cloud service model and network model, this paper defines the concept of "Internet" business model. Cloud service model mainly use the information management system of cloud environment or cloud platform embedded into the organization, based on the IT infrastructure, through data collection, data integration, data storage. Data organization, data analysis and data presentation to provide cloud services to users of Zhu Zongqian (2017) [3] that in data centric cloud service model, access to data is simplified, but due to the popularity of network interaction, need to increase the capacity of relational database management system. By the way of cloud deployment, effectively reduce the cost. At the same time connected through with the increase of users and reduce deployment time, its characteristic is to enhance the scalability, integration and ease of use of. Changlong Tang (2015) [4] that in the cloud service mode, The user will focus on cloud security risks, such as data leakage, data loss, denial of service, cloud mixed, sharing technology gives users the security risk of. $\mathrm{O} 2 \mathrm{O}$ channel model is the electronic commerce mode based on online interaction, which is different from the traditional enterprise through television advertising, open sales channels imageprolocutor way of communication with the user in full play, big data management, based on the precision marketing and other advantages, make full use of online and offline channels to their respective advantages, to achieve interoperability, the goal is to maximize the use of enterprise resource. The empirical study shows that the industrial Internet has an impact on the business model of enterprises (Daniel Kiel, 2017) [5]. Enterprises from the seller or the manufacturer has become the advanced technology service provider. Xingang Weng (2015) [6] that the online business has the advantages of low cost, small inventory risk characteristics, The store's competitive advantage is to consider the needs of users and to provide good service, online and offline integration way more conducive to the establishment of three-dimensional network business model. Crowdsourcing mode is the enterprise value chain of some links through the Internet platform outsourcing to social participation and cooperation, emphasizing the public force value then, the formation of a new mode of production,. Gouillart elements and the labor organization (2010) [7] proposed "groups to create the experience of cooperation" ideas, that user experience is the core of enterprise value creation, organization of users, employees and stakeholders to work together, is the correct way to produce creative Wang Shu. Regarded as resources in the organization, operation and work together to achieve the value, in the field of information technology, business and knowledge in the field of innovation as the theme of the effect.

\subsection{Conceptual Data Modeling}

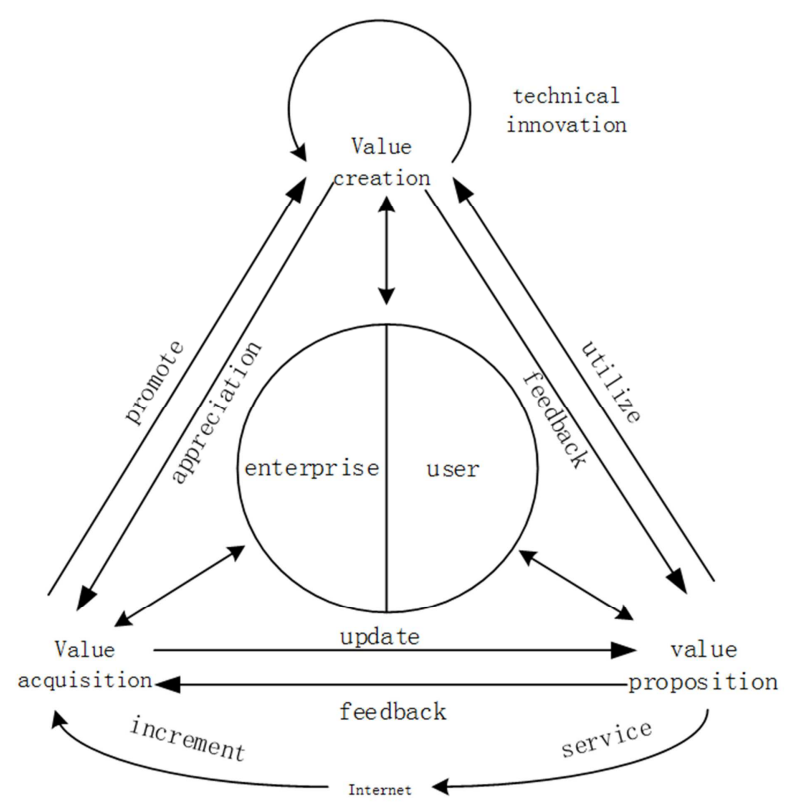

Figure 1. Conceptual model map of the Internet business model.

For the "Internet" business model definition: traditional enterprise and the Internet industry after the fusion of the products online and data processing using the Internet technology, the user centered thinking, business logic through dynamic marketing mode to realize the value creation. The concept of business model, referring to the conceptual model of Zott: refers to the logic of designing system value creation, value transfer and value acquisition. figure 1 is the "Internet" concept of business model.

\section{Empirical Analysis}

\subsection{Sample Description}

\subsubsection{Questionnaire Design}

This paper combined with the research ideas, the main contents of the questionnaire for the value proposition of the determinants of Internet business model innovation, resources and capabilities, external cooperation and financial network four elements are designed based on the questionnaire, the questionnaire consists of the following parts: first, the questionnaire design. This section contains the questionnaire the topic, significance and background, as well as instructions and precautions, to ensure the validity of the 
questionnaire; second of respondents, the basic information design. This section includes respondents age, gender, engaged in manufacturing related work on time, "the Internet" understanding, understanding of the basic situation of the survey was third; the questionnaire, the main part of the design, mainly from the value proposition, the resources and abilities. The investigation of 33 factors four aspects of external cooperation and financial network, respondents according to their own To determine the cognitive level of influencing factors; fourth, open topic design, this part is a supplement to the questionnaire

\subsubsection{Data Collection}

In order to ensure the accuracy of the survey questionnaire and the rationality of the design, mainly to the research team members, engaged in emerging industry management school MBA members started pre research as the object, a total of 60 questionnaires were issued, 52 questionnaires were recovered, the recovery rate of $86.67 \%$ was modified on the pre survey results of response, continuity and important the number of training out of key business partners, to ensure the validity of the questionnaire.
This questionnaire aims to influence the investigation of the "Internet" business model innovation identification factors, in a formal investigation, aiming at the enterprise level operators, managers, consumers and business models of the questionnaire, to take multi-channel, multi site questionnaire, such as scene, letter, e-mail network connection, telephone access, etc., in Xi'an, Xiamen, Chengdu, Chongqing, Shenzhen and other regions issued a total of 280 copies, the total recovery of 255 , excluding the high vacancy rate, the answer is not complete 14 invalid questionnaires, 241 copies of questionnaires. The actual residual rate was $91.07 \%$, the effective recovery rate was $86.07 \%$. in on the understanding and analysis of the questionnaire, the respondents for the open question understanding visit and summary, to eliminate the influence of subjective factors on the questionnaire cross understanding and cross validation using the way. In the 241 valid questionnaires, the participants' gender, age, educational background, participant contact with social media, participation in non work enterprises production and business activities were statistically analyzed to grasp the characteristics of the survey sample, the results shown in Table 1 .

Table 1. Statistics of sample basic information.

\begin{tabular}{|c|c|c|c|}
\hline Sample basic information & Project & Number of people & Scale \\
\hline \multirow{2}{*}{ Sex } & man & 135 & $56.02 \%$ \\
\hline & woman & 106 & $43.98 \%$ \\
\hline \multirow{5}{*}{ Age } & Under 22 years old & 11 & $4.56 \%$ \\
\hline & $23-28$ & 40 & $16.60 \%$ \\
\hline & $29-35$ & 92 & $38.17 \%$ \\
\hline & $35-44$ & 63 & $26.14 \%$ \\
\hline & Above 45 years old & 35 & $14.53 \%$ \\
\hline \multirow{3}{*}{ Record of formal schooling } & Junior College & 46 & $19.09 \%$ \\
\hline & Undergraduate & 69 & $28.63 \%$ \\
\hline & Graduate student & 107 & $44.40 \%$ \\
\hline \multirow{4}{*}{ Social media approach } & WeChat & 229 & $95.02 \%$ \\
\hline & micro-blog & 112 & $46.47 \%$ \\
\hline & forum & 38 & $15.77 \%$ \\
\hline & Podcast & 14 & $5.81 \%$ \\
\hline \multirow{3}{*}{$\begin{array}{l}\text { Participation in production and operation } \\
\text { interaction times }\end{array}$} & 2 times and below & 156 & $64.73 \%$ \\
\hline & $6-10$ & 17 & $7.05 \%$ \\
\hline & More than 10 times & 0 & $0 \%$ \\
\hline
\end{tabular}

\subsection{Identification of Influencing Factors of Internet Business Model Innovation}

"The process of value transmission due to the impact of the Internet business model innovation, the focus of enterprise with stakeholders to establish good communication and cooperation, realize the enterprise value creation thinking of using the Internet and new technology by logic, value proposition, resources and capabilities, external cooperation and financial network four elements to analyse the influence of the" Internet "business model innovation factors.

\subsubsection{Value Proposition}

The "Internet" environment, enterprises in considering the operation of products and business users have problems when companies first consider the contact or service is user groups, target users become the influence factors of "Internet" business model innovation. Jiang Jihai (2015) [8] in that community for the greatest common divisor of the business environment, enterprises need to pay attention to customer value and explore market segments, user behavior, psychological and social aspects with similar features; Feng Hua (2016) [9] believes in the Internet economy, the fragmentation of the user thinking performance for users at the same time can do more things, and flexible, flexible timing arrangements, time perception the level of different users, choice of services is different, thereby affecting the company's business model; Feng Xuefei (2015) [10] that the behavior of the mainstream customer attention enterprise is the logical self Selection and edge customers with long-term potential, enterprises need to pay the effort can find the edge customers to expand the regional market factors influence the 
target user as shown in Table 2.

Table 2. User impact factors of innovation goal of "Internet" business model.

\begin{tabular}{ll}
\hline Number & Influencing factors of "Internet" business model innovation \\
\hline 1 & target user characteristics \\
2 & users' perceived value of time \\
3 & enterprises pay attention to edge users \\
\hline
\end{tabular}

The age of the Internet, business products is the foundation of business management, explains the value proposition for customers to purchase or use products or services to, or service it contains optional products, in order to cater to the specific requirements of customer groups, and to achieve the ultimate product excellence, enterprises demand content has become influence factors of "Internet" business model innovation. The "Internet" environment, the business scope extends to different products or services in different markets, showing significant differences, showing the trend of diversification; Chen Yu (2015) [11] proposed a "1= ten" thinking, innovative ideas inspired product positioning of the clothing enterprises, will in the enterprise business and then combined with the realization of the value of decomposition, to meet the personalized needs of niche, demand factors affecting the content are shown in Table 3.

Table 3. Factors influencing the demand for business model innovation of the Internet.

\begin{tabular}{ll}
\hline Number & Influencing factors of "Internet" business model innovation \\
\hline 1 & Change of business scope of enterprise products \\
2 & Enterprise product positioning innovation \\
\hline
\end{tabular}

\subsubsection{Value Proposition}

Enterprise resource integration refers to enterprises owned or needs of the various elements in the "Internet" environment resources integration includes corporate reputation, human resources, data, software and other content core resources become ". Gao factors of the Internet" business model innovation (2008) [12] [33] that staff absorption and utilization of external knowledge is ability an important part of enterprise business model innovation; Higgins (2006) [13] that the senior managers of enterprises through interaction with key stakeholders to influence stakeholder awareness of the enterprise, when executives with strong technical ability or market ability, are more likely to be recognized by customers; Christina $H$ (2013) [14] that the age of the Internet, data has become the key factor of production of enterprises, the enterprise's economic activities have been cannot do without data assets; Guo zhe (2015) [15] that good sound Reputation can bring positive effect to the enterprise, the enterprise reputation capital based on value proposition, value network, value maintenance and value realization layer effect, to achieve the process of reputation capital; interconnection by the Internet business, for non core operation through the external timing piece flexible way to complete it focus on the enterprise core resources, virtual human effective influence of enterprise operation efficiency, influence factors of core resources as shown in Table 4.
Table 4. Influencing factors of core resources of "Internet" business model innovation.

\begin{tabular}{ll}
\hline Number & Influencing factors of "Internet" business model innovation \\
\hline 1 & Knowledge absorptive ability of employees inside enterprises \\
2 & Top management market capacity \\
3 & Ratio of data assets to total assets \\
4 & Corporate reputation capital \\
5 & Effectiveness of virtual human resources \\
\hline
\end{tabular}

It is implemented by the key business, thereby improving overall efficiency, key business includes manufacturing, consulting and training content and network relationship, become the key business factors of Internet business model innovation. The basic condition of "Internet" is the enterprise with "Internet" hardware facilities; Piller (2015) [16] that remanufacturing technology provides a new opportunity to create and capture value for personalized products, enterprises need to explore new business models in emerging technology under the background of Bulger; (2014) [17] that the data application potential of the enterprise business model determines the driving strength, and then decide on the strength business model innovation; security data security includes data storage, data access permissions, data privacy and reliable data transmission Of different positions in different enterprises for the visibility of the data, thereby affecting the range of technical services business model; value-added service is under the premise of ensuring the stability of the basic service, personalized service for scale users, and value-added services can imitate the decision to choose innovative enterprises or learning business model; the focus of the enterprise on-demand service reduces the information service threshold at the same time, creates time and space for enterprises to enhance their business critical, critical business continuity of culture is the reflection of the business model of competitive advantage, the key factors affecting business as shown in Table 5 .

Table 5. Key factors affecting business model innovation of "Internet".

\begin{tabular}{ll}
\hline Number & Influencing factors of "Internet" business model innovation \\
\hline 1 & Hardware infrastructure construction \\
2 & Application of remanufacturing technology in Enterprises \\
3 & Big data resource utilization and management capability \\
4 & Enterprise data security \\
5 & The imitation of enterprise value added service \\
6 & Continuity of key business ability training \\
\hline
\end{tabular}

\subsubsection{External Cooperation Network}

The customer is not the passive subject, and will actively participate in the entire business process. The integration of the Internet under the background of Internet and traditional manufacturing enterprises through the depth to the intermediary, the user directly tracking survey, and constantly improve the products / services offered by the user to contact the user, users to establish a good relationship with optimization the. Heli factors of the Internet users to become "business model innovation (2014) [18] that the products to provide experience for the users of the service, to meet the individual needs of users, under the new economic 
environment, the user has" guilt "psychological experience for free service, this kind of psychological urges the user purchase behavior; Wang Xiaoyu (2014) [19] that the social platform user generated content (UGC) will have a direct impact on the credibility of the brand focus of enterprise brand attitude positive effects and negative effects, because The adoption UGC extent of the customer's purchasing decision behavior; Wisner (2008) [20] that user integration refers to information exchange and cooperation between business processes and enterprise user focus, user integration of the production activities and services, with related information and decision flow, based on user community interaction the expression of sharing, cooperative production, word-of-mouth behavior; Wang Qiaoyu (2015) [21] that users provide suggestions to enterprises reflects the identity of enterprise customers, enterprises to adopt feedback information can stimulate user feedback behavior, and enhance the enterprise trust and loyalty; Li Yao (2014) [22] that customer production is self motivation, opportunity and ability of interaction results, the production results below user expectations, the users of the enterprise evaluation, has a significant effect on purchase intention and word-of-mouth publicity will follow User impact factors are shown in Table 6.

Table 6. User impact factors of "Internet" business model innovation.

\begin{tabular}{ll}
\hline Number & Influencing factors of "Internet" business model innovation \\
\hline 1 & Users' acceptance of products through free experience \\
2 & Users' adoption of content generated by social platform users \\
3 & $\begin{array}{l}\text { Users' emotional involvement based on brand community } \\
\text { interaction }\end{array}$ \\
5 & User information feedback adoption ratio \\
\hline
\end{tabular}

Partners can describe the effective functioning of the business model on the downstream cooperation network required, enterprises need to know the important partners of their own, the core resource identification from partners get and key business, to help enterprises to better focus the target user's value creation activities, access to resources and optimize the business model in reducing risk under the condition that the partners become ". Stuart factors of the Internet" business model innovation (2002) [23] that the widespread connection between partners can help enterprises to obtain more extensive and comprehensive knowledge, information and opportunity, possibility of achieving economies of scale and scope more; key technology partners to provide resources the focus relates to whether the enterprise needs to maintain the lease relationship and channel cooperation partners; cross category business can make clear The root of the problem of their own business, and adjust their market positioning, channel resources cooperation become the enterprises with the industry's leading brands segment opportunities; Zhang Baosheng (2015) [24] that willingness to cooperate is precondition to select partners, in the "Internet" environment, the "user centric" thinking whether in the embodiment of partners to provide customized service, with cooperation partners to achieve business negotiations consensus, partner factors are shown in Table 7.

Table 7. Influencing factors of innovation partners in "Internet" business model.

\begin{tabular}{ll}
\hline Number & Influencing factors of "Internet" business model innovation \\
\hline 1 & Number of important partners \\
2 & Technical facility resources of partners \\
3 & Channel resources of partners \\
4 & Cooperative willingness of partners \\
\hline
\end{tabular}

The establishment of cooperative network is to optimize the allocation of resources, extend the industrial chain of the enterprise, so as to reduce the operating costs of enterprises, to achieve resource sharing, complementary advantages, network relationship has become influence factors of "Internet" business model innovation. Fang Benxin (2008) [25] that the stability of the partners are more familiar with each other, have a good cooperation, there is a clear expectation of their future prospects, trust each other to simplify the tedious process, and Peng Xinmin (2009) [26] that excessive stable partnership may increase corruption, maintain the relationship between the cost, causes the enterprise indirect costs rise, the partner group is too old, the enterprise value network become closed and rigid, so the network innovation lose diversity; Wang Liping (2016)[27] considered complementary resources to influence prices through interactive ability and network relationship strength Industry cooperation network innovation performance, complementary cooperation network to sustainable development of business ecosystem; Huang Changsheng (2016) [28] that only achieve stakeholdersvalue profit growth, with a reasonable profit distribution mechanism to achieve win-win cooperation and achieve win-win cooperation to promote the development of the network, the network influence factors as shown in Table 8 shows.

Table 8. Factors influencing the innovation network relationship of "Internet" business model.

\begin{tabular}{ll}
\hline Number & Influencing factors of "Internet" business model innovation \\
\hline 1 & Stability of cooperative networks \\
2 & Cooperative network complementarity \\
3 & Win win cooperation network \\
\hline
\end{tabular}

\subsubsection{Finance}

Enterprises in the understanding of user segments of willingness to pay, in order to find one or more sources of income in each user segments, understand the payment way by the user. To obtain the corresponding income recognition enterprises to create activities in the process of value, in general, the business model can contain the following two revenue sources: trading income get through the user one-time payment, recurring costs from the user to obtain the value proposition and customer service service and continue to pay; enterprises choose to provide product / service pricing to users. The Internet environment forced enterprises to expand business innovation and sustained profitability, 
revenue channels is corresponding with the business development evolved a lot; provide payment in the current society, Yang Luming (2016) [29] that will affect the user perceived benefit and perceived risk, using different methods of payment, The payment behavior of the user through the use of experience and pay based on the consideration of the enterprise, become an important reference of user payment behavior; Tao (2012) [30] Based on the information transfer from the perspective of the cost of products, the analysis of user behavior, proposed the product pricing strategy establishment stage of the corporate profits are the most direct way, income factors sources of influence are shown in Table 9 .

Table 9. Influencing factors of revenue sources of "Internet" business model innovation.

\begin{tabular}{ll}
\hline Number & Influencing factors of "Internet" business model innovation \\
\hline 1 & Pricing strategy of products \\
2 & Innovation of enterprise income channel \\
3 & Payment method \\
\hline
\end{tabular}

To describe the cost structure of the enterprise to create value, provide value to maintain customer relationship, produce all kinds of costs caused by income and other activities, identify the enterprise to create the necessary input costs in the process of value activities; to spend the most content understanding of core resources and key business, analysis the most important costs inherent in the business model (Yang Haoxiong. 2016) [31] to network about cars subsidies platform as an example, analysis of the impact of price subsidies on car about profits, enterprises can take the price subsidies to the user's strategy, although the increase in cost, but to expand sales through win-win realization of enterprise and user; Wu Juhua (2013) [32] that the service provider to provide dynamic service according to user needs, to form a flexible pay way, improve the enterprise's business ability, cost factors are shown in table 10 .
Table 10. Influencing factors of innovation cost of "Internet" business model.

\begin{tabular}{ll}
\hline Number & Influencing factors of "Internet" business model innovation \\
\hline 1 & Price cross subsidy mechanism \\
2 & Pay-as-you-go \\
\hline
\end{tabular}

\section{Empirical Results Analysis}

\subsection{Reliability and Validity Analysis}

The reliability of questionnaire in repeated measurement, the statistical results of the degree of consistency. The reliability of the original data to reflect the reliability and stability of the internal consistency reliability usually represents the level. The reliability coefficient in the $0 \sim 1$ range, the value is close to 1 , the test results showed that the questionnaire is close to more stable; 0 , the test results showed that the questionnaire is reliable. The clone of Bach (Cronbach) Cronbach alpha coefficient to test the questionnaire, in general, the Cronbach alpha coefficient of more than 0.8 have use value. This paper uses the SPSS20.0 questionnaire for the "Internet" business model innovation factors and test results are as follows. The Cronbach coefficient is $0.840>0.8$ show the internal consistency of the questionnaire design is reasonable, the reliability is good.

The use of KMO and Bartley (Bartlett) ball type test $p$ value of. Kaiser to test the applicability of factor analysis that KMO value can reflect the size suitable for factor analysis of the level, the greater the value, the higher the level of KMO, more than 0.9 in a completely suitable level, more than 0.8 are in good level for more than 0.7 , in the middle for the level. In the lower level for more than 0.6 , more than 0.5 at the lowest level, if less than 0.5, is not suitable for factor analysis; the Bartlett coefficient is greater than 0.01 , is also not suitable for factor analysis. This paper uses the SPSS20.0 software to get the test results are shown in Table 11, KMO value is $0.898>0.8$, the test of Bartlett ball type $\mathrm{P}$ value was 0 . The original data show that a sufficient sample size, suitable for factor analysis.

Table 11. Sphericity test and KMO test of Bartley.

\begin{tabular}{lll}
\hline Test of KMO and Bartlett & & \\
\hline & Kaiser-Meyer-Olkin metrics for sampling sufficiency & $\mathbf{. 8 9 8}$ \\
\hline \multirow{3}{*}{ Sphericity test of Bartlett } & Approximate chi square & 6497.451 \\
& df & 465 \\
& Sig. & .000 \\
\hline
\end{tabular}

\subsection{Factor Analysis}

After inputting the data of 241 questionnaires into SPSS20.0, the common factor variance extraction value is shown in table 12:

Table 12. Variance of common factor

\begin{tabular}{|c|c|c|}
\hline \multicolumn{3}{|l|}{ Common factor variance } \\
\hline & Initial & extraction \\
\hline Target user characteristics & 1.000 & .705 \\
\hline Time value perception of users & 1.000 & .780 \\
\hline Enterprises pay more attention to marginal users & 1.000 & .750 \\
\hline Change of business scope of enterprise products & 1.000 & .695 \\
\hline Enterprise product positioning innovation & 1.000 & .744 \\
\hline Knowledge absorptive ability of employees inside enterprises & 1.000 & .744 \\
\hline
\end{tabular}




\begin{tabular}{|c|c|c|}
\hline \multicolumn{3}{|l|}{ Common factor variance } \\
\hline & Initial & extraction \\
\hline Ratio of data assets to total assets & 1.000 & .745 \\
\hline Corporate reputation capital & 1.000 & .753 \\
\hline Effectiveness of virtual human resources & 1.000 & .739 \\
\hline Hardware infrastructure construction & 1.000 & .750 \\
\hline Application of remanufacturing technology in Enterprises & 1.000 & .763 \\
\hline Big data resource utilization and management capability & 1.000 & .775 \\
\hline The imitation of enterprise value added service & 1.000 & .672 \\
\hline Users' acceptance of products through free experience & 1.000 & .760 \\
\hline Users' adoption of content generated by social platform users & 1.000 & .812 \\
\hline Users' emotional involvement based on brand community interaction & 1.000 & .781 \\
\hline User information feedback adoption ratio & 1.000 & .799 \\
\hline User self production & 1.000 & 689 \\
\hline Technical facility resources of partners & 1.000 & .793 \\
\hline Stability of cooperative networks & 1.000 & .708 \\
\hline Cooperative network complementarity & 1.000 & .769 \\
\hline Win win cooperation network & 1.000 & .742 \\
\hline Pricing strategy of products & 1.000 & .665 \\
\hline Innovation of enterprise income channel & 1.000 & .666 \\
\hline Payment method & 1.000 & .668 \\
\hline Price cross subsidy mechanism & 1.000 & .688 \\
\hline Pay-as-you-go & 1.000 & .654 \\
\hline
\end{tabular}

Extraction method: principal component analysis.

The gravel map is used to represent the feature reduction factor in the process of value dimension and quantity, ideal for a gravel map after bending gradually approaching the level, tend to be less likely to smooth factor variation, can be neglected. By using the statistical software of SPSS20.0 factor analysis showed that the gravel is shown in Figure 2, eigenvalue greater than 1 factors there are 4 obvious inflection point, a total of 4 , since the fifth factor eigenvalue was stable, the first 4 ingredients extraction of the questionnaire information was explained.

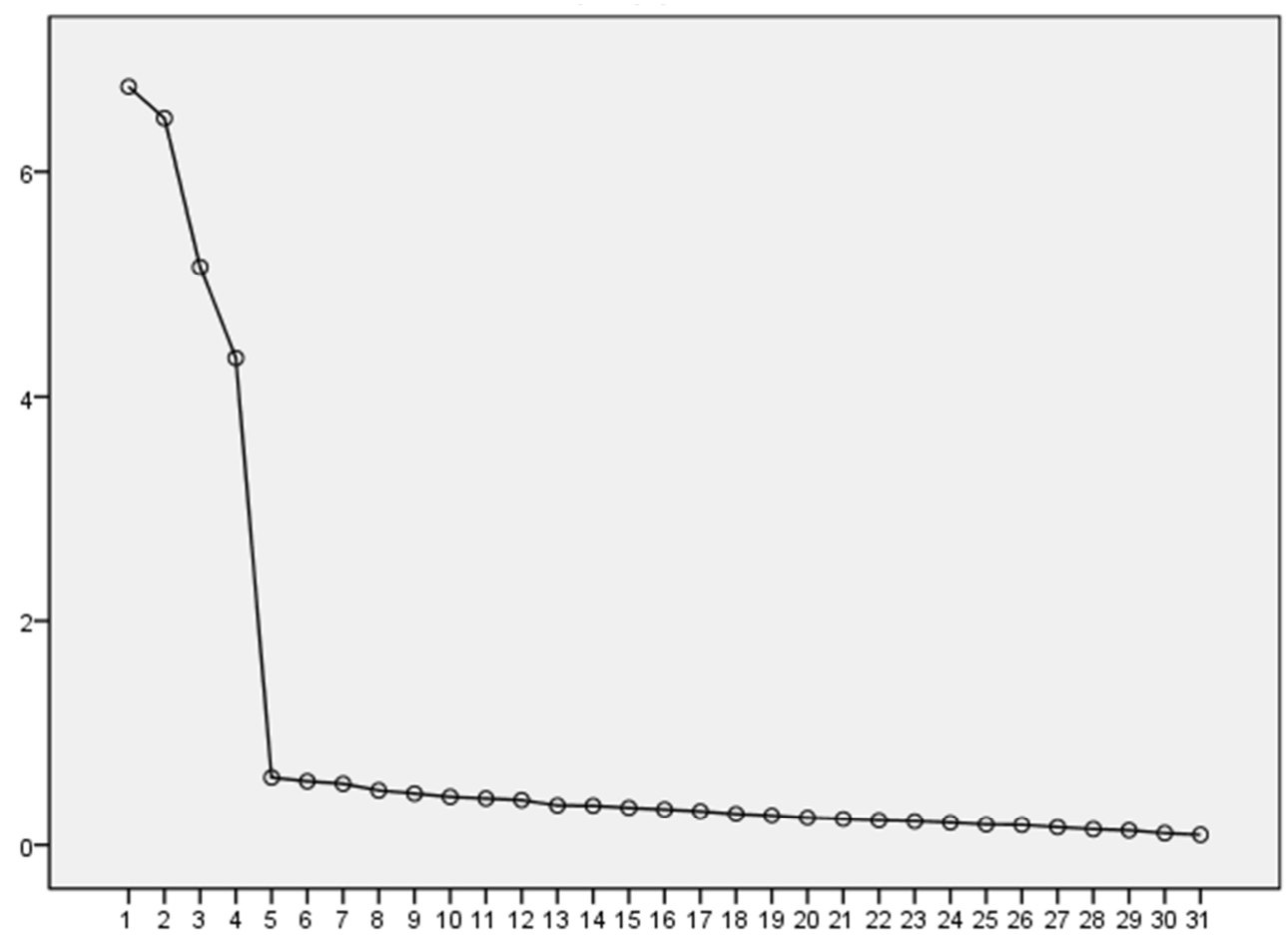

Figure 2. Principal component macadam map.

The total explained variance components used to illustrate the contribution to the original variable information rate, as shown in table 13, the first 4 ingredients extracted from the original $73.371 \%$ factors can explain the information in the questionnaire, 
characteristic factor $1,2,3,4=6.77,6.48,5.15,4.34$ is greater than 1 , in line with the principle of factor analysis, the first 4 factors are the main "the Internet business model innovation factor" 31 factors.

Table 13. Extraction and analysis of principal components of variance decomposition.

\begin{tabular}{|c|c|c|c|c|c|c|c|c|c|}
\hline \multicolumn{10}{|c|}{ Total variance of interpretation } \\
\hline \multirow{2}{*}{ Ingredients } & \multicolumn{3}{|c|}{ Initial eigenvalue } & \multicolumn{3}{|c|}{ Extract sum of squares load } & \multicolumn{3}{|c|}{ Rotation sum of squares loading } \\
\hline & Total & Variance\% & Cumulative\% & Total & Variance\% & Cumulative\% & Total & Variance\% & Cumulative\% \\
\hline 1 & 6.765 & 21.822 & 21.822 & 6.765 & 21.822 & 21.822 & 6.486 & 20.923 & 20.923 \\
\hline 2 & 6.483 & 20.914 & 42.736 & 6.483 & 20.914 & 42.736 & 5.601 & 18.067 & 38.990 \\
\hline 3 & 5.154 & 16.626 & 59.362 & 5.154 & 16.626 & 59.362 & 5.469 & 17.642 & 56.632 \\
\hline 4 & 4.343 & 14.009 & 73.371 & 4.343 & 14.009 & 73.371 & 5.189 & 16.739 & 73.371 \\
\hline 5 & .605 & 1.952 & 75.323 & & & & & & \\
\hline 6 & .572 & 1.844 & 77.167 & & & & & & \\
\hline 7 & .550 & 1.775 & 78.942 & & & & & & \\
\hline 8 & .491 & 1.583 & 80.526 & & & & & & \\
\hline 9 & .463 & 1.495 & 82.020 & & & & & & \\
\hline 10 & .433 & 1.398 & 83.418 & & & & & & \\
\hline 11 & .419 & 1.351 & 84.769 & & & & & & \\
\hline 12 & .405 & 1.307 & 86.076 & & & & & & \\
\hline 13 & .357 & 1.152 & 87.228 & & & & & & \\
\hline 14 & .355 & 1.145 & 88.373 & & & & & & \\
\hline 15 & .335 & 1.080 & 89.453 & & & & & & \\
\hline 16 & .320 & 1.033 & 90.486 & & & & & & \\
\hline 17 & .304 & .981 & 91.466 & & & & & & \\
\hline 18 & .280 & .903 & 92.369 & & & & & & \\
\hline 19 & .265 & .853 & 93.222 & & & & & & \\
\hline 20 & .245 & .791 & 94.014 & & & & & & \\
\hline 21 & .234 & .755 & 94.769 & & & & & & \\
\hline 22 & .221 & .714 & 95.483 & & & & & & \\
\hline 23 & .213 & .688 & 96.171 & & & & & & \\
\hline 24 & .201 & 647 & 96.818 & & & & & & \\
\hline 25 & .183 & .589 & 97.407 & & & & & & \\
\hline 26 & .179 & .578 & 97.986 & & & & & & \\
\hline 27 & .159 & .514 & 98.499 & & & & & & \\
\hline 28 & .140 & .453 & 98.952 & & & & & & \\
\hline 29 & .130 & .421 & 99.373 & & & & & & \\
\hline 30 & .104 & .336 & 99.709 & & & & & & \\
\hline 31 & .090 & .291 & 100.000 & & & & & & \\
\hline
\end{tabular}

Extraction method: principal component analysis.

\subsection{Factor Naming}

Due to the factors of load of more than two and higher with a factor component in the matrix, in order to distinguish the meaning of each component factor better explained the meaning of using the maximum variance method of factor load matrix after orthogonal rotation, rotation matrix components are shown in table 14.

Table 14. Rotation component matrix.

\begin{tabular}{|c|c|c|c|c|}
\hline \multicolumn{5}{|l|}{ Rotational component matrix } \\
\hline & \multicolumn{4}{|c|}{ ingredient } \\
\hline & 1 & 2 & 3 & 4 \\
\hline Target user characteristics & .874 & .046 & -.032 & -.042 \\
\hline Time value perception of users & .862 & -.002 & -.020 & -.009 \\
\hline Enterprises pay more attention to marginal users & .861 & .019 & .056 & -.004 \\
\hline Change of business scope of enterprise products & .858 & -.038 & -.004 & -.025 \\
\hline Enterprise product positioning innovation & .844 & .003 & .037 & .011 \\
\hline Top management market capacity & .836 & .057 & .007 & .060 \\
\hline Ratio of data assets to total assets & .832 & .004 & .034 & -.034 \\
\hline Corporate reputation capital & .820 & -.014 & .009 & -.001 \\
\hline Effectiveness of virtual human resources & -.012 & .866 & -.047 & .015 \\
\hline Hardware infrastructure construction & .000 & .862 & -.082 & .016 \\
\hline Application of remanufacturing technology in Enterprises & -.049 & .851 & -.119 & .012 \\
\hline Big data resource utilization and management capability & .066 & .825 & -.052 & .021 \\
\hline The imitation of enterprise value added service & .018 & .811 & -.081 & -.018 \\
\hline
\end{tabular}




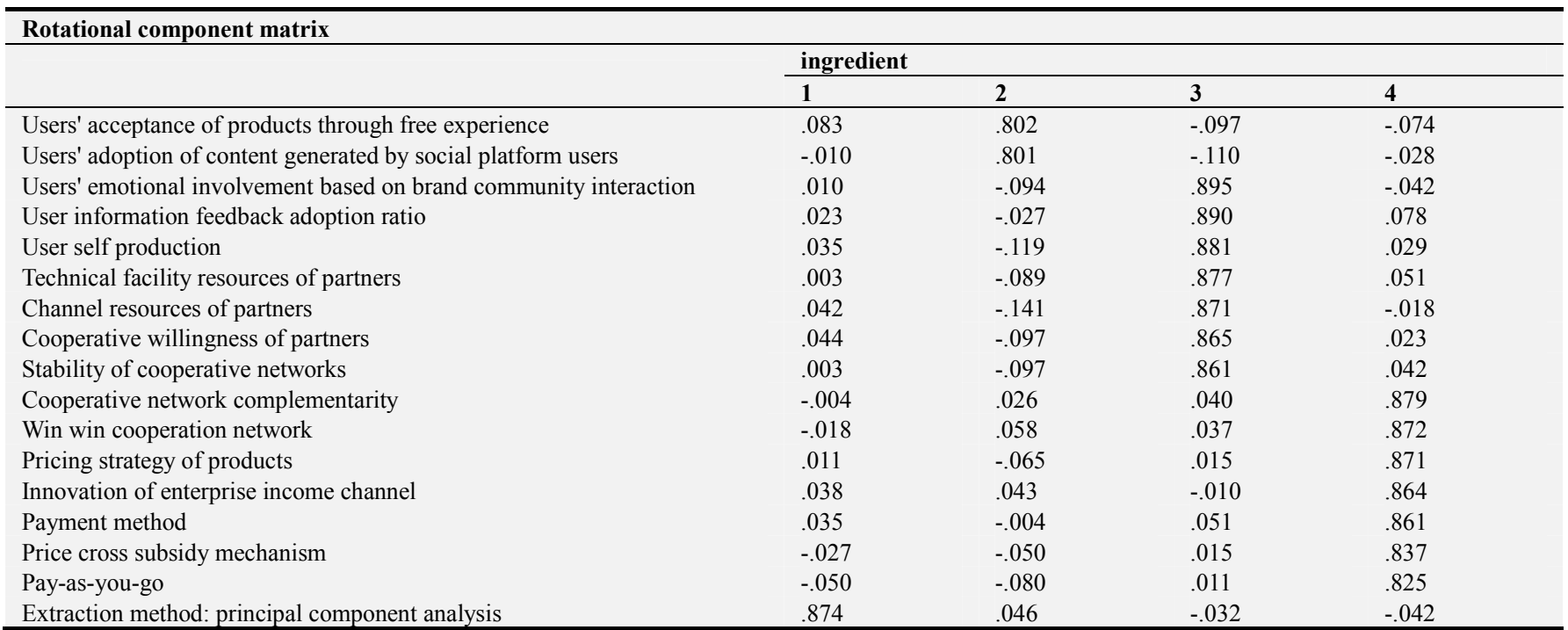

Extraction method: principal component

Rotation method: orthogonal rotation method with Kaiser standardization

The A. rotation converges after the 5 iteration

Accordingly, this paper extracted a total of "Internet" business model innovation of four common factors, namely the integration of industrial chain drive body, degree of two-way flow of value, internal and external resources integration and profit.

A driver named as the main factor integration of industrial chain, which is composed of the target user characteristics, data assets as a percentage of total assets, infrastructure construction, application of remanufacturing technology in the enterprise, and the management ability of the use of large data resources, enterprise data security, consisting of seven factors of partnership technical facilities and resources. The seven factors of reaction the virtual enterprise and virtual environment is becoming the new consumer experience products and services, through the development of intelligent, intelligent production, to achieve the transformation and upgrading of the real economy to the sales of smart intelligent distribution, using digital consumer preferences, online and manufacturing of flexible supply channels to form new forms of real and virtual time fusion.

The two factor named $\mathrm{Bi}$ value flow, which consists of the user time value perception, senior managers market ability, the user through the free experience for product acceptance, acceptance of user generated content on social platform users, users based on brand community interaction emotion input, user information feedback, the adoption rate, composition of self production seven factors of users. Seven factors reflect the enterprise and the user contact is no longer one-way transfer to the traditional enterprise user's value, forming a two-way circulation enterprise to the user to the enterprise value delivery, the user is no longer the recipient information and products, and become the demand and release of service, the user experience and suggestions gradually as part of a marketing channel.

The three factor named enterprise resources integration, which is composed of enterprise product scope changes, enterprise product positioning and innovation, the enterprise employees' knowledge absorptive capacity, the effectiveness of the virtual human resource, enterprise value-added services can be imitated, partner channel resources, partners will, the stability of cooperation network, complementary cooperation network nine factors. The nine factors reflect the oligopoly enterprises more and more, a dominant situation is eliminated, new industry market access threshold is more and more low among enterprises to achieve the integration of resources through different channels and different point of view, cooperation management strategy to promote the focus of enterprise core resources into the advantage of business links, to integrate internal and external resources is conducive to the realization of cross industry.

The four factor named the profits obtained by the enterprise, it emphasis on the edge users, corporate reputation capital, win-win cooperation network, product pricing strategy, enterprise income channel innovation, mode of payment, the price of cross subsidy mechanism, pay eight factors. The eight factors reflect the enterprises have already bid farewell to the products as the main the profit source of profits, the rational allocation of resources in response to user demand from the user process, mining, business development, payment environment change, marketing innovation in various ways to change the original profit model, the establishment of community and platform not only enables the user demand precision at the same time, training users personalized needs paying habits.

\section{Conclusion}

Through the analysis of the principal components of the innovation of the "Internet +" business model, four dimensions reflecting the innovation of the "Internet + " business model are obtained: the integration of the industrial chain driving the main body, the degree of value flow. Among 
them, the internal and external resources integration is the driving factor of value creation based on the strategic perspective, and the profit acquisition is the driving factor of value creation based on the financial perspective. It belongs to the category of value creation mode, and the profit acquisition method can be divided into internal resource sharing type according to the emphasis of internal and external resource integration in the process of value creation. Therefore, the innovation dimension of Internet business model is the driving force of industrial chain convergence, and the degree of value flow. Enterprise internal and external resources integration and profit acquisition.

In order to promote the innovation of enterprise's Internet business model, the enterprise should strengthen the complementarity and stability of the cooperative network and expand the channel resources of the partner from the dimension of the industry chain and the driving agent. Strengthen the knowledge absorption ability of the employees and the innovation ability of the enterprise product positioning, and control the replicability of the enterprise value-added service on the basis of ensuring the data security of the enterprise. Enterprises should pay more attention to marginal users, strengthen the win-win nature of enterprise cooperation networks and innovation of revenue channels. From the perspective of internal and external resources integration, enterprises should strengthen communication with users and master user self-production. Based on the interactive emotional input of brand community, the proportion of user feedback and acceptance, and the acceptance of product through free experience, the user innovates the Internet business model. On the basis of enterprise data security, the enterprise makes use of big data resources and Internet technology to innovate from the way of obtaining profits.

The above research can draw the influence factors of the innovation of "Internet" business model. In the future research, it will be important to examine the influence of various factors on business model innovation. In order to provide theoretical support for business model innovation.

\section{References}

[1] Dan Fengru, Wang Tong. Based on the "Internet" formula for China's retail enterprises 020 business model innovation mechanism and modeling of J. Journal of Bohai University (NATURAL SCIENCE EDITION), 2015, 03:242-248..

[2] Liu Zhou. Research on Internet and industrial cluster Internet upgrade $[\mathrm{J}]$. Science and technology management, 2015, 08:73-82.

[3] Zhu Zongqian, Ma Xiqiang, Shang Yanying. Research on SaaS ERP Service provider selection Model based on risk Control [J]. Research on Productivity, 2017, 08:1-7.

[4] Changlong Tang, Jiqiang Liu. Selecting a Trusted Cloud Service Provider for your SaaS Program [J]. Conputers \& Security, 2015, 50:60-73.

[5] Daniel Kiel, Christian Arnold, Kai-Ingo Voigt. The influence of the Industrial Internet of Things on business models of established manufacturing companies - A business level perspective [J]. Technovation 68 (2017) 4-19.

[6] Xingang Weng, Liying Zhang. Analysis of O2O Model's Development Problems and Trend [J]. IBusi-ness, 2015, 7:51-57.

[7] Gouillart F, Ramaswami V. Building the Cocreative Enterprise [J]. Harvaed Business Review, 2010, 88 (10):100-109.

[8] Jiang Jihai. Business model is the "old wine in a new bottle"? academic controversy, the dominant logic and theoretical foundation of J. Research and development management, 2015, 02:12-24.

[9] Feng Hua, Chen Yaqi. Research on the innovation of platform business model -- spatio temporal fit analysis based on the Internet environment $[\mathrm{J}]$. Chinese industrial economy, 2016, 03:99-113.

[10] Feng Xuefei, Dong Da, Zhang Ruixue. Internet thinking: a shortcut for Chinese traditional enterprises to realize business model innovation $[\mathrm{J}]$. Contemporary economic management, 2015, 04:20-23.

[11] Chen Yu. The application of "one $1=$ ten" thinking in the localization and development of small and medium sized clothing enterprises in Min faction [J]. Journal of Xiamen University of Technology, 2015, 04:13-18.

[12] Gao S. Managerial Ties, Absorptive Capacity and Innovation [J]. Asia Pacific Journal of Management, 2008, 25 (3):395-412.

[13] Higgins M, Gulati R. Stacking the deck: the Effects of Top Management Backgrounds on Investor Decisions [J]. Strategic Management Journal, 2006, 27 (1):1-25.

[14] Christina H, etal. Big Data and the Creative Destruction of Today's Business Models [R]. AT Kearney, 2013.

[15] Guo Zhe. Corporate reputation capital on the business model of the impact mechanism of J. The financial times, 2015, 21:71-72.

[16] Piller, F, Weller, C. Business Models with Additive Manufacturing: Opportunities and Challenges form the Perspective of Economics and Management [J]. Advances in Production, 2015, 15 (4):39-48.

[17] Bulger M, Taylor G, Schrieder R. Data-Driven Business Models Challenges and Opportunities of Big Data [R]. Oxford Internet Institute University of Oxford, 2014.

[18] Heli Holttinen. Contextualizing Value Propositions: Examining How Consumers Experience Value Propositions in Their Practices [J]. Australasian Marketing Journal, 2014, 22 (14):103-110.

[19] Wang Xiaoyu, Zheng Yaqin. A review of the impact of UGC on brand attitude in the context of social business [J]. Journal of Zhengzhou Institute of Aeronautics Industry Management, 2014, 03:78-81.

[20] Wisner J, Tan k, Leong K. Principles of Supply Chain Management: A Balanced Approach [M]. Mason, OH: South-Western, 2008.

[21] Wang Qiaoyu, Qian Huimin,. Money online and offline channels of financing business model analysis based on $\mathrm{J}$. Business studies, 2015, 20:9-11. 
[22] Li Yao. Customers create value individually under customer dominant logic: An Empirical Study Based on the perspective of cognitive interaction [J]. Chinese industrial economy, 2014, 01:101-113.

[23] Stuart, Bames. The Mobile Value Chain: A nalysis and Future Developments [J]. International Journal of Information Management, 2002, (22):91-108.

[24] Zhang Baosheng, Zhang Qingpu. Research on the factors influencing the willingness of cooperation of tacit knowledge transfer network based on grounded theory [J]. Journal of management, 2015, 08:1224-1229.

[25] Fang Benxin, Zhang Ning. Value network: the innovative significance and function from the cultural perspective $[\mathrm{J}]$. Research management, 2008, 01:138-143187.

[26] Peng Xinmin. Relationship between network connection and organizational performance from contingency perspective $[\mathrm{J}]$. Research management, 2009, 03:47-55.

[27] Wang Liping, He Yarong. Complementary resources, interactive capabilities and cooperative innovation performance [J]. Science research, 2016, 01:132-141.

[28] Huang Changsheng, Yu Hongxian. Internet enterprises to participate in energy cooperation under the effects of Lotka-Volterra model based on the analysis of J. Chinese and foreign energy, 2016, 04:14-21.
[29] Yang Luming, Shan Liang, Wu Yana. The choice of payment method to predict the tendency of the traditional financial analysis of the effect of J. Journal of Guizhou University of Finance and economics, 2016, 04:57-68.

[30] Tao Ran. China C2C shopping site pricing strategy based on cost analysis from the perspective of $\mathrm{J}$ transfer of information products. Journal of Postgraduates in Huazhong Normal University, 2012, 02:157-162.

[31] Yang Haoxiong, Wei Bin. A game study on the competition between online taxis and taxis -- Based on platform subsidy [J]. Beijing Social Sciences, 2016, 05:68-76.

[32] Wu Juhua, Cao Qiang, Li Pinyi, et al. Research on the progress of cloud computing -- Based on the dual perspectives of technology and Commerce [J]. Science and technology management research, 2013, 15:23-28.

[33] Federico Cosenz, Guido Noto. A dynamic business modelling approach to design and experiment new business venture strategies [J]. Long Range Planning, 2018, 51: 127-140.

[34] Fredrik Hacklin, Joakim Bjorkdahl, Martin W. Wallin. Strategies for business model innovation: How firms reel in migrating value [J]. Long Range Planning, 2018, 51:82-110. 